\title{
EDUCAÇÃO AMBIENTAL E BACIAS HIDROGRÁFICAS NO CONTEXTO ESCOLAR
}

\author{
Thayline Vieira Queiroz 1 \\ Carolina Buso Dornfeld 2
}

\section{RESUMO}

A pesquisa ressalta a importância da educação ambiental como referência socioambiental para o conjunto de práticas educativas, articulada ao contexto das bacias hidrográficas. O estudo foi realizado junto aos alunos de $6^{\circ}$ ano do Ensino Fundamental de uma escola privada, localizada em llha Solteira/SP. As atividades foram organizadas em aulas práticas e teóricas com enfoque na região de llha Solteira e na Bacia Hidrográfica do rio São José dos Dourados. A discussão e análise da pesquisa encontra-se estruturada a partir do instrumento metodológico do Grupo Focal, proposta por Gui (2003). Para a interpretação dos dados foi utilizada a análise de conteúdo, de acordo com os princípios sistematizados em Bardin (2010). Verificou-se que os recursos metodológicos utilizados constituíram um grande facilitador para a obtenção do aprendizado dos alunos, em relação ao conceito de bacia hidrográfica que deve ser trabalhado nas escolas de forma interdisciplinar, para a compreensão de que a mesma constitui um sistema complexo de interações entre os componentes biológicos, geológicos, hidrológicos e antropogênicos em uma região, contemplando-se mais estudos que mostrem à comunidade. Além disso, constatou-se que a técnica do Grupo Focal caracterizouse como um excelente espaço de reflexão. Os sujeitos da pesquisa consideraram que as interações foram importantes momentos de troca de experiências e reflexão da própria prática como aprendizagem para o grupo.

Palavras-chave: Educação ambiental. Ensino fundamental. Grupo focal.

\section{ENVIRONMENTAL EDUCATION AND WATERSHEDS IN THE SCHOOL CONTEXT}

\section{ABSTRACT}

\footnotetext{
1 Mestre em Ensino e Processos Formativos pela Universidade Estadual Paulista Júlio de Mesquita Filho - UNESP/IBILCE/InterUnidades. Orcid iD: https://orcid.org/ 0000-0003-2105-5505. E-mail: thaylinequeiroz@gmail.com

2 Doutora em Ciências da Engenharia Ambiental pela Universidade de São Paulo. Professora do Programa Multidisciplinar InterUnidades de Pós-Graduação Strictu Sensu "Ensino e Processos Formativos" da Universidade Estadual Paulista Júlio de Mesquita Filho (UNESP São José do Rio Preto/llha Solteira e Jaboticabal). Orcid iD: https://orcid.org/ 0000-0003-44257062. E-mail: caroldornfeld@gmail.com
} 
The research highlights the importance of environmental education as a social and environmental reference for the set of educational practices articulated to the context of the hydrographic basins. The study was carried out with the 6th grade elementary students of a private school located in Ilha Solteira / SP. The activities were organized in practical and theoretical classes focusing on the region of llha Solteira and the Hydrographic Basin of the São José dos Dourados river. The discussion and analysis of the research is structured using the methodological tool of the Focal Group, proposed by Gui (2003). For the interpretation of the data was used the content analysis, according to the principles systematized in Bardin (2010). It was verified that the methodological resources used were a great facilitator to obtain students' learning in relation to the concept of watershed that must be worked in the schools in an interdisciplinary way, in order to understand that it constitutes a complex system of interactions between the biological, geological, hydrological and anthropogenic components in a region, contemplating further studies that show the community. In addition, it was found that the technique of the focal group was characterized as an excellent space for reflection. The subjects of the research considered that the interactions were important moments of exchange of experiences and reflection of the practice itself as learning for the group.

Keywords: Watersheds. Environmental education. Elementary School. Focus group.

\section{EDUCACIÓN AMBIENTAL Y BACIAS HIDROGRÁFICAS EN EL CONTEXTO ESCOLAR}

\section{RESUMEN}

La investigación resalta la importancia de la educación ambiental como referencia socioambiental para el conjunto de prácticas educativas articuladas al contexto de las cuencas hidrográficas. El estudio fue realizado junto a los alumnos de $6^{\circ}$ año de la Enseñanza Fundamental de una escuela privada ubicada en llha Solteira / SP. Las actividades fueron organizadas en clases prácticas y teóricas con enfoque en la región de llha Solteira y en la Cuenca Hidrográfica del río São José dos Dourados. La discusión y análisis de la investigación se encuentra estructurada a partir del instrumento metodológico del Grupo Focal, propuesta por Gui (2003). Para la interpretación de los datos se utilizó el análisis de contenido, de acuerdo con los principios sistematizados en Bardin (2010). Se verificó que los recursos metodológicos utilizados constituyeron un gran facilitador para la obtención del aprendizaje de los alumnos en relación al concepto de cuenca hidrográfica que debe ser trabajado en las escuelas de forma interdisciplinaria para la comprensión de que la misma constituye un sistema complejo de interacciones entre los componentes biológicos, geológicos, hidrológicos y antropogénicos en una región, contemplando más estudios que muestren a la comunidad. Además, se constató que la técnica del grupo focal se caracterizó como un excelente espacio de reflexión. Los sujetos de la investigación consideraron que las interacciones fueron importantes momentos de intercambio de experiencias y reflexión de la propia práctica como aprendizaje para el grupo.

Palabras clave: Cuencas hidrográficas. Educación ambiental. Enseñanza fundamental. Grupo focal. 


\section{INTRODUÇÃO}

Embora ainda que desarticuladas e de forma gradual, compreensões e concepções na área da Educação Ambiental, que incorporam novas perspectivas estão aos poucos ganhando espaços, em diferentes ambientes educativos. Temas que remetem à problemática ambiental têm sido bastante discutidos na sociedade promovendo repercussão global.

Nessa perspectiva, é evidente a necessidade da educação contemporânea buscar uma ciência contextualizada, capaz de contribuir para uma melhor aprendizagem do aluno, que garanta a formação de cidadãos conscientes e comprometidos com a construção de uma sociedade sustentável, pois "a educação é a chave, em qualquer caso, para renovar os valores e a percepção do problema, desenvolvendo uma consciência com compromisso que possibilitem a mudança, e a participação coletiva na resolução dos problemas" (DIAS, 1992, p. 44).

De acordo com Penteado (2001), a Educação Ambiental se torna uma importante ferramenta política e pedagógica para a busca da integração entre as disciplinas escolares privilegiando a abordagem das Ciências Naturais e Sociais de forma a ultrapassar as abordagens preservacionista e conservacionista e, deflagrando discussões mais aprofundadas sobre política, cultura, meio ambiente, sociedade e ética. Dessa forma, torna a escola o local ideal para promover este processo, considerando as disciplinas escolares como recursos didáticos, por meio dos quais, os conhecimentos científicos de que a sociedade já dispõe são colocados ao alcance dos alunos.

Diante do exposto acima, observa-se que a escola também é considerada como um espaço privilegiado para estabelecer essas conexões e informações, como uma das possibilidades para criar condições e alternativas que estimulem os alunos a terem concepções e posturas cidadãs, cientes de suas responsabilidades e, principalmente, perceberemse como integrantes do meio ambiente. Portanto, continua sendo um "espaço importante para o desenvolvimento de valores e atitudes 
comprometidas com a sustentabilidade ecológica e social" (LIMA, 2004, p.01).

Neste sentido, "enfatiza-se, assim, a urgência da implantação de trabalhos de Educação Ambiental (EA) que contemplem as questões da vida cotidiana do cidadão e discutam algumas visões polêmicas sobre essa temática" (BRASIL, 1998, p.169), considerando a importância atribuída à EA como meio indispensável para conseguir criar e aplicar formas cada vez mais sustentáveis de interação da sociedade com a natureza e soluções para os problemas ambientais.

É necessário "reconhecer que, para apreender sobre a problemática ambiental, precisa-se de uma visão complexa do meio ambiente, e que a natureza integra uma rede de relações não apenas naturais, mas também sociais e culturais" (CARVALHO, 2008, p.34). Neste contexto, segundo Ruffino e Santos (2002), a abordagem de bacias hidrográficas é considerada como unidade representativa próxima a vivências dos educadores e de seus alunos. De acordo com os autores, "abrange conhecimentos interrelacionados e aspectos complexos, como a disponibilidade e o uso da água, a importância ambiental, econômica, política e social dos rios que formam as principais bacias hidrográficas brasileiras". Para tanto, é imprescindível a percepção ambiental em relação aos aspectos biofísicos e antrópicos. Assim, de acordo com Reigota (1998), é possível adquirir um entendimento do ambiente em sua plenitude, da problemática que está relacionada a ele e da responsabilidade de cada um diante dessas questões.

Portanto, considera-se que a Educação Ambiental pode constituir-se como centralidade de referência socioambiental para o conjunto de práticas educativas no território geográfico de cada bacia hidrográfica. Além disso, considera-se que é necessário levar os alunos a refletir e perceber o quanto é importante o estudo de uma bacia hidrográfica, realizando o levantamento de questões que interferem no cotidiano de sua comunidade. Dessa forma, pode-se inferir que o aprendizado embasado no estudo de bacias hidrográficas é essencial para que os alunos comecem a 
pensar na atividade antrópica incorporada no meio ambiente e nas relações de causa e efeito que isso gera no bem-estar sócio ambiental.

\section{Objetivo Geral}

O presente trabalho teve como objetivo analisar possíveis interpretações de alunos do $6^{\circ}$ ano do Ensino Fundamental sobre a temática das bacias hidrográficas, a partir de um trabalho pedagógico que toma como referência elementos que constituem a Educação Ambiental. Além disso, desenvolver junto aos participantes uma visão mais crítica e reflexiva sobre as questões ambientais locais e regionais. Por último, analisar as contribuições da metodologia do Grupo Focal como ferramenta de análise qualitativa na pesquisa em Educação Ambiental.

\section{Objetivos específicos}

- Propiciar condições para que os alunos reflitam sobre a importância da bacia hidrográfica como um sistema complexo, com a interação entre os elementos ecológicos, sociais e econômicos;

- $\quad$ Desenvolver uma abordagem interdisciplinar do tema, utilizando diferentes recursos didáticos, tais como estratégias de leitura de imagens de satélite, maquetes e mapas;

- $\quad$ Desenvolver uma sequência didática para uma aprendizagem significativa dos conceitos de: bacias hidrográficas, microbacias, uso e ocupação do solo e conservação da biodiversidade;

- Analisar como os alunos se envolveram com as atividades do projeto, e identificar possíveis alterações nas interpretações dos alunos em relação ao conceito de bacia hidrográfica;

\section{MATERIAL E MÉTODO}

\section{Área de Estudo}

O presente trabalho foi desenvolvido em um projeto extraclasse, denominado de "Biologia Muito Além da llha: Sem Limites para o Conhecimento", desenvolvido em parceria com a Pró - Reitoria de Extensão 
Universitária da UNESP. O projeto contou com a participação de, aproximadamente, 20 alunos do $6^{\circ}$ ano do ensino fundamental. As atividades foram realizadas em parceria com uma escola privada da cidade de llha Solteira-SP e desenvolvidas no LECBio (Laboratório de Ensino de Ciências e Biologia), localizado no Câmpus II da UNESP - Iha Solteira.

O projeto conta com uma autorização de uso de imagem dos alunos participantes para fins científicos e acadêmicos, que foi assinada pelos pais ou responsáveis, conta com 0 apoio da Direção e Coordenação Pedagógica da Instituição de Ensino e, também, com a autorização da Direção da Escola para que o nome da instituição pudesse ser citado neste texto.

\section{Procedimentos Metodológicos}

Para a realização do projeto utilizou-se a pesquisa qualitativa, que permite explorar as características dos indivíduos e cenários que não podem ser facilmente descritos numericamente. O dado é, frequentemente, verbal e é coletado pela observação, descrição e gravação (MOREIRA; CALEFFE, 2008, p. 73).

Foram realizadas reuniões semanais com os membros do projeto, bem como com a Coordenação Pedagógica e os professores responsáveis pelas disciplinas de Ciências e Geografia para a discussão dos referenciais teóricos e elaboração das atividades didáticas.

O registro geral das atividades foi realizado por meio de fotos ou imagens, registro do produto final dos trabalhos dos alunos, como por exemplo: os trabalhos desenvolvidos nas saídas de campo, a construção de maquetes, cartazes e Notas de Campo. Para a coleta de dados, também foi utilizada a metodologia do Grupo Focal, que tem por finalidade proporcionar um momento de troca de conceitos, atitudes, condições de discussão sobre o tema e maior integração entre os participantes. Segundo Gui (2003), o Grupo Focal: 
[...] não se busca o consenso e sim a pluralidade de ideias. Assim, a ênfase está na interação dentro do grupo, baseada em tópicos oferecidos pelo pesquisador, que assume o papel de moderador. 0 principal interesse é que seja recriado, desse modo, um contexto ou ambiente social onde $o$ indivíduo pode interagir com os demais, defendendo, revendo, ratificando suas próprias opiniões ou influenciando as opiniões dos demais. Essa abordagem possibilita também ao pesquisador aprofundar sua compreensão das respostas obtidas (GUI, 2003, p.140).

O que se pode destacar como peculiaridade desse método é a interação que acontece entre um conjunto de pessoas ao serem convidadas a debater um tema levantado pelo pesquisador, que, normalmente, tem o papel de moderador da discussão. Os dados utilizados na análise dessa interação são as transcrições das discussões do grupo que foram registrados em áudio e vídeo (Kodak V1073- Touch Screen), e a ênfase na busca de ideias trazidas coletivamente, e não individualmente.

Para a análise e interpretação dos dados, foi utilizada a análise de conteúdo, de acordo com os princípios sistematizados em Bardin (2010). Trata-se, de um procedimento que consiste na análise dos dados qualitativos através da identificação de temáticas que constituem resposta a questões específicas.

Foram realizados cinco encontros, com duração de duas horas, durante os quais foram abordados tópicos sobre as questões ambientais de interesse. As atividades didáticas elaboradas foram realizadas na seguinte ordem:

Atividade 1 - Discussão a respeito da importância dos recursos hídricos, elaboração de cartazes em grupos sobre bacias hidrográficas e suas características, debates e busca de alternativas para a solução do estudo de caso que tratava sobre a gestão e preservação dos recursos hídricos.

Atividade 2- Foi abordado o tema "Microbacias", com o enfoque na Bacia Hidrográfica $(\mathrm{BH})$ do Rio São José dos Dourados, riscos ambientais na região, preservação, com o auxílio da Imagem de Satélite do Google Maps e Imagem da Bacia Hidrográfica do Rio São José dos Dourados (CBH-SJD, 2013). Ao final do encontro, foi realizado uma Roda de Conversa, utilizando a metodologia do Grupo Focal. Foi elaborado um roteiro com perguntas 
norteadoras, a fim de auxiliar na progressão e no enriquecimento da reunião: (Roteiro 1- O que vocês entendem por bacias hidrográficas? O que é uma microbacia para você? O município que você mora faz parte de qual bacia hidrográfica? Qual a atividade predominante e os principais impactos presentes na bacia hidrográfica de seu município? O que são unidades de gerenciamento, para que são importantes? O que vocês sabem sobre o Rio São José dos Dourados? O que ele significa para a cidade?; Qual a importância de preservarmos nossa bacia ?; Quais medidas de conservação você sugere?

Atividade 3- Confecção de maquetes para representação da bacia hidrográfica - região de llha Solteira-SP. Durante a confecção dos materiais, buscou-se a compreensão da bacia hidrográfica enquanto espaço geográfico de identidade, de trabalho e produção econômica, trazendo para o debate as características da região e seus recursos naturais (florestas, solos, águas, etc).

Atividade 4- Atividade de campo. Percepção ambiental dos alunos por meio de registros fotográficos. Uma das intenções principais da aula de campo foi levar a turma a compreender a paisagem (a união de elementos naturais e construídos pelo homem em determinado espaço), entendendo as relações biológicas, sociais e econômicas que a estruturam.

Atividade 5- Foi realizada a reunião final de encerramento do projeto, e, posteriormente, os alunos participaram do último Grupo Focal que trouxe como reflexão tópicos que foram abordados nos encontros anteriores. (Roteiro 2- Faça uma análise de relação entre os temas: Ecossistemas e bacias hidrográficas; Como as funções dos animais (aquáticos ou terrestres) podem influenciar no equilíbrio de um ecossistema ou bioma? Diferencie Ecossistemas e biomas; Quais instrumentos utilizados na gestão dos recursos hídricos. Relacione um instrumento com o outro; O que é uma bacia hidrográfica/microbacia? O que é uma unidade de gerenciamento de recursos hídricos? Se você fosse o prefeito de uma cidade, o que você faria para solucionar tais problemas: Falta de mata ciliar e falta de arborização na cidade?" 
Deve-se salientar que os alunos não foram identificados nas transcrições de suas respostas e que foram mantidos os possíveis erros de português, como grafia das palavras e concordância.

\section{RESULTADOS E DISCUSSÃO}

A seguir serão apresentados os resultados obtidos durante os encontros realizados com os alunos. A título de melhor organização, os mesmos estão separados em Atividades realizadas.

\section{Atividade 1}

Durante o primeiro contato com o tema, foi possível notar que a maioria dos alunos não possuía conhecimento sobre a bacia hidrográfica da região, tampouco, as complexas relações que podem ser trabalhadas com esta temática. Ficou evidente, nos depoimentos dos alunos, que a temática sobre bacias hidrográficas tem sido trabalhada apenas de forma tradicional nas escolas, sem a existência de articulações entre as disciplinas. Com base nesse enfoque, questões sobre características gerais, localização com auxílio de mapas, uso e ocupação do solo, foram aprofundadas a fim de caracterizar melhor a bacia São José dos Dourados. Portanto, este primeiro encontro, visou colocar os alunos diante da realidade da dimensão ambiental, bem como thes proporcionar a ampliação de alguns conhecimentos gerais.

Após a discussão do estudo de caso apresentado, que tratava sobre a gestão e preservação dos recursos hídricos, alguns alunos apresentaram possíveis sugestões:

A1."Eu instalaria um sistema de água que dependendo do horário dez horas abre o registro e a hora que for três horas, fecha. Duas horas da manhã abre de novo para quando as pessoas acordarem terem água para tomar banho e escovar os dentes. Mas eu queria que todas as casas tivessem cisternas para captar a água da chuva para a reutilização de água, acho que seria a melhor maneira"

A2."Eu iria fazer um poço grande, captaria a água da chuva e ao mesmo tempo passaria por um processo de tratamento e iria para as casas 
para ser utilizada para lavar louça e roupa. No caso, São Paulo está com problema e várias pessoas estão sem água, as vezes por horas e às vezes por dias. Por isso, as vezes pegam um balde e pegam a água da chuva e seria uma boa ideia para essa época de crise"

Os alunos mencionaram a crise hídrica em São Paulo como exemplo durante as discussões sobre o estudo de caso. A preocupação dos demais em relação ao consumo de água foi demonstrada em mudanças de hábitos como sugestões, porém observa-se em vários momentos que os alunos preconizaram a punição e não a conscientização da população, a maioria chegou à conclusão de que são necessárias medidas que visem o planejamento adequado e a reutilização de água da chuva principalmente. Durante o debate, ficou evidente que o estudo de caso contribuiu no aprendizado dos alunos, pois foram direcionados a agirem como solucionadores de problema e tomadores de decisão.

Neste sentido, Tozoni Reis (2007) ressalta que a educação pode ser transformadora se garantir aos alunos os instrumentos necessários para agirem de forma emancipada, pela transformação das relações sociais de dominação. "Na educação ambiental, essas ideias configuram uma pedagogia crítica cuja contextualização histórica e social dos saberes é elemento fundamental dos processos educativos" (TOZONI REIS; 2007, p.14).

Se tomarmos a educação ambiental para a sustentabilidade como
eixo da pedagogia crítica da educação ambiental, temos que sua
proposta pedagógica objetiva uma ação educativa na formação
de sujeitos sociais críticos e participativos na construção de uma
sociedade sustentável, entendida como uma sociedade responsável
pela qualidade do ambiente em que vive em sua dimensão natural
mas também em sua dimensão social, valorizando, além da
diversidade e do equilíbrio ambiental a democracia, a equidade
social, a justiça, a autonomia e a emancipação dos sujeitos (TOZONI
REIS; 2007, p.15).

Em continuidade, os alunos confeccionaram cartazes, representando por meio de desenhos e colagens como interpretam o território geográfico da bacia hidrográfica (Figura 1). 
FIGURA 01 - Representação da Bacia Hidrográfica São José dos Dourados (A. Dupla 1; B. Dupla 2; C. Dupla 3; D: Dupla 4)
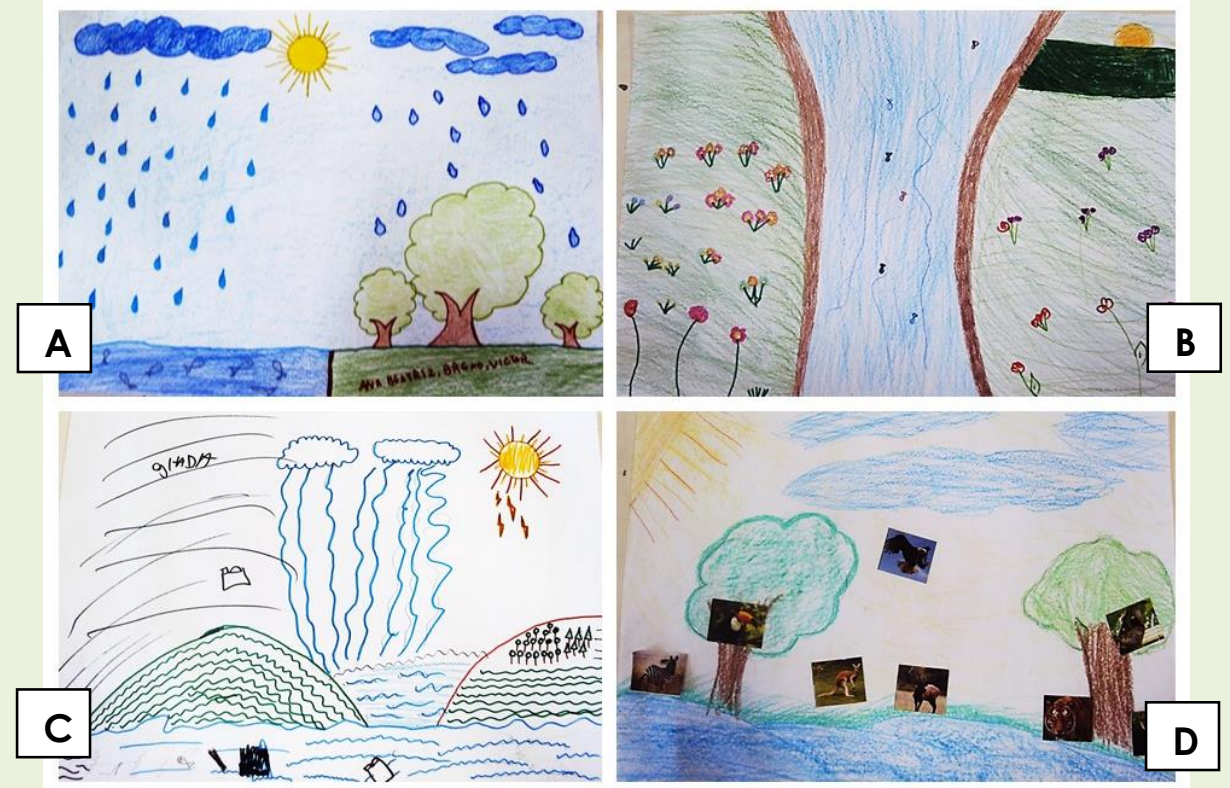

Fonte: Próprio autor.

Conforme discutido por Bezerra e Gonçalves (2007), em relação ao termo "meio ambiente", constantemente utilizado tanto em meios de comunicação como nos discursos políticos, livros didáticos, músicas e outras fontes, existe uma grande diversidade conceitual, possibilitando diferentes interpretações, muitas vezes, influenciadas pela vivência pessoal, profissional e pelas informações veiculadas na mídia.

Os cartazes confeccionados pelos alunos mostraram uma concepção de Bacia Hidrográfica estritamente relacionada aos aspectos físicos e naturais, excluindo o ser humano e todas as suas intervenções no meio, ou seja, uma predominância pela visão biocêntrica, sendo que as representações realizadas pelos alunos dispensaram totalmente os componentes sociais referentes ao meio. Pode-se relacionar esta abordagem de bacia hidrográfica com uma apresentação de visão na qual o ser humano é circundado pelo ambiente sem ser parte integrante deste, apresentada em Reigota (2001).

Para Oliveira (2000), o desafio da questão ambiental, por sua extensão e complexidade, vem exigindo uma abordagem cada vez menos ortodoxa, rompendo com a tradição segmentada e reducionista, tornando-se 
necessária a consolidação de um entendimento mais amplo do processo de Educação Ambiental. Na mesma perspectiva, Dias (1992) ressalta que é necessário constituir uma educação permanente que inclua todos os aspectos que a compõem, possibilitando que se compreenda o ambiente na sua interdependência com o homem, com as consequências das ações humanas do presente para o futuro, constituindo uma visão crítica da realidade ambiental.

Tudo leva a crer que a Educação Ambiental só apresentará resultados coerentes se implementar em seu fazer cotidiano, a completa contextualização da complexidade ambiental. Para isso, corroborando com Tozoni-Reis (2015), é imprescindível o envolvimento das dimensões social, econômica, política, ideológica, cultural e ecológica do problema ambiental, em suas conexões territoriais e geopolíticas, provocando não apenas as transformações culturais que possam conduzir a uma ética ambiental, mas também, em mudanças sociais necessárias para a construção de uma sociedade ecologicamente responsável e socialmente justa, incentivando não apenas ação individual e comportamentalista, mas também a ação coletiva na esfera pública.

Portanto, torna-se importante a discussão em torno das diferentes concepções sobre meio ambiente articuladas ao contexto das bacias hidrográficas, principalmente com o intuito de despertar uma análise crítica da realidade ambiental.

\section{Atividade 2}

O foco do encontro, além dos conceitos básicos já mencionados, percorreu na importância da preservação das microbacias bem como sua importância para a sobrevivência dos seres vivos e a preservação de um dos bens mais vitais para os seres vivos na Terra, no caso, a água.

Apesar de algumas limitações já esperadas, os estudantes demonstraram possuir conhecimento básico sobre microbacias. É interessante ressaltar que eles conseguiram assimilar corretamente informações que foram abordadas nos encontros anteriores, reunindo em 
tópicos as principais questões que foram discutidas, como pode ser evidenciado pelos relatos a seguir:

A1. "O rio, o rio principal e os outros menores, plantações, as coisas ao redor, tudo!"

A2."São os pequenos rios que formam uma bacia inteira, lembro algo do tipo".

A3. "Nos mapas apareceram algumas coisas, eu não tinha entendido muito bem, só depois que deu pra ver que 'tava' interligando um rio no outro."

A4. "É... da pra ver mesmo que são vários caminhos, ele tipo abastece o rio que fica maior, né?!"

\section{Atividade 3}

Observou-se que a atividade de montagem da maquete proporcionou a interação entre os alunos, como também a sua participação ativa, ou seja, foram estimulados a confrontar suas ideias com os demais. Foi possível verificar que essa interação auxiliou os alunos na construção do seu saber, abrindo-se um espaço para abordarem questões de interesse durante o desenvolvimento das atividades. No exemplo abaixo, apresenta-se uma situação que revela o posicionamento de alguns alunos durante a fase de construção da maquete.

A1. "Vamos colocar duas áreas, uma poluída e outra não poluída, porque aí dá pra gente colocar tudo que tem em uma bacia hidrográfica"...

A2. "Dá pra representar e relembrar a importância das matas ciliares e o problema do assoreamento aqui na bacia, como vimos na outra atividade aula passada"...

A3. "Os animais também, não tem só cidade,"...

A1. "Também, mas acho melhor representar a ocupação das casas, pra mostrar que dependemos dessa água, porque não são só as plantas e os animais que fazem uso dela, e também nem é todo rio que tem mata ciliar, acho que aqui nem deve ter" (...)

Nota-se que, a partir das discussões durante a montagem do material, os alunos demonstraram melhor compreensão sobre todos os aspectos que envolvem a bacia hidrográfica da região. Assim, conforme menciona 
Thiesen (2008), na sala ou em qualquer outro ambiente de aprendizagem, são várias relações que contribuem no processo de construção e organização do conhecimento.

As múltiplas relações entre professores, alunos e objetos de estudo constroem o contexto de trabalho dentro do qual as relações de sentido são construídas. Nesse complexo trabalho, o enfoque interdisciplinar aproxima o sujeito de sua realidade mais ampla, auxilia os aprendizes na compreensão das complexas redes conceituais, possibilita maior significado e sentido aos conteúdos da aprendizagem, permitindo uma formação mais consistente e responsável (THIESEN, 2008, p.551).

Nesta perspectiva, considera-se que a interação em sala de aula também pode servir como um importante instrumento no processo de ensino- aprendizagem.

Percebeu-se uma tomada de consciência dos estudantes sobre temas como o uso e ocupação do solo, importância da vegetação e possiviveis consequências negativas na ausência das matas ciliares. O confronto de ideias desencadeou reflexões que contribuíram para a escolha de um modelo em comum, no qual foi possível abordar todos os componentes de uma bacia hidrográfica, na versão final da maquete, conforme demonstrado na figura abaixo (Figura 2).

FIGURA 02 - Representação da bacia hidrográfica finalizada pelos alunos

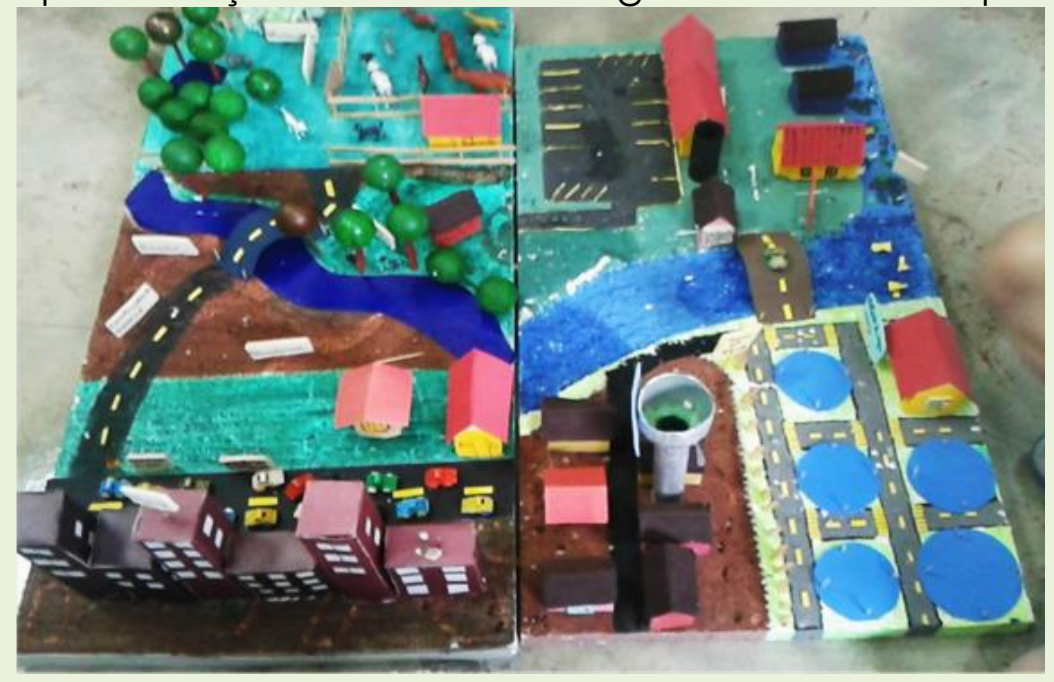

Fonte: Próprio autor 
Segundo Moraes et al (2012), a atividade proposta utilizando materiais de fácil acesso representa um pequeno exemplo de como as aulas teóricas e as atividades práticas podem se desvincular de amarras tradicionais, e partir para um novo patamar de construção do saber. Assim, ele menciona que "quando se consegue fazer com que a teoria se integre à prática ocorre o aprofundamento de conhecimento em sala de aula, entretanto, as atividades práticas, independente dos conceitos abordados, despertam o interesse entre os alunos de qualquer nível escolar" (Moraes et al., 2012, p.62).

No caso específico, os conceitos teóricos sobre bacias hidrográficas, que são considerados pelos alunos de difícil assimilação e compreensão, tornaram-se mais acessíveis, devido ao caráter motivador das atividades práticas.

Portanto, pode-se destacar que as maquetes colaboraram positivamente e foram indispensáveis para a explicação de fenômenos que estão essencialmente presentes no espaço geográfico e que muitas vezes são de difícil compreensão, quando analisados em mapas ou apenas abordados teoricamente nas aulas de Ciências e Geografia.

\section{Atividade 4}

Ao realizar a atividade de campo com a turma, pretendia-se chamar a atenção dos alunos sobre a importância da preservação do ambiente e despertar a consciência ecológica nos mesmos, ao fazê-los observar e sentir a natureza, assim como identificar os problemas provocados no ambiente pela ação humana.

Durante a atividade de campo, viveu-se um momento instigante com os alunos, no decorrer do percurso foi notável a ansiedade dos mesmos e curiosidade em aprender mais sobre os elementos observados: "Nossa que árvore é aquela?", "Por causa dela que esta bem mais fresco aqui, não é? olha o tamanho dela!". Assim, "Sair do ambiente escolar, por si só, gera um efeito geralmente positivo sobre o interesse dos alunos pelo conteúdo" (FARINA; GUADAGNIN, 2007, p.111). 
Além disso, segundo Carvalho (1998), as atividades de campo podem ser utilizadas como importante estratégia em programas de EA, uma vez que o contato com o ambiente permite a sensibilização dos alunos acerca dos problemas ambientais. No momento dessas atividades, surgiram oportunidades de reflexão sobre valores, não só imprescindíveis às mudanças comportamentais e atitudinais, mas também a respeito das questões sociais, políticas e econômicas que envolvem essa temática.

Após a atividade de campo, os alunos retornaram para o laboratório didático (LECBio), onde foi realizada uma discussão em grupo e debatidos alguns elementos analisados nas fotos registradas no decorrer da atividade (Figura 3).

A atividade de retorno à sala de aula completa aquilo que no campo escapou, ficou subentendido ou mal-entendido. Ela ultrapassa o momento de reunião das entrevistas, fotografias e narração das melhores vivências (OLIVEIRA; ASSIS, 2009, p. 201).

Portanto, buscou-se, nesse sentido, despertar a interação e o diálogo entre os alunos, instigando-os a darem suas opiniões, fazer suas críticas ou comentários sobre os temas abordados tanto nas aulas teóricas como na atividade de campo.

FIGURA 03 - Fotos tiradas pelos alunos - no entorno do Campus II-Unesp- Iha Solteira- SP; (A e B. Grupo 1; C e D. Grupo 2)
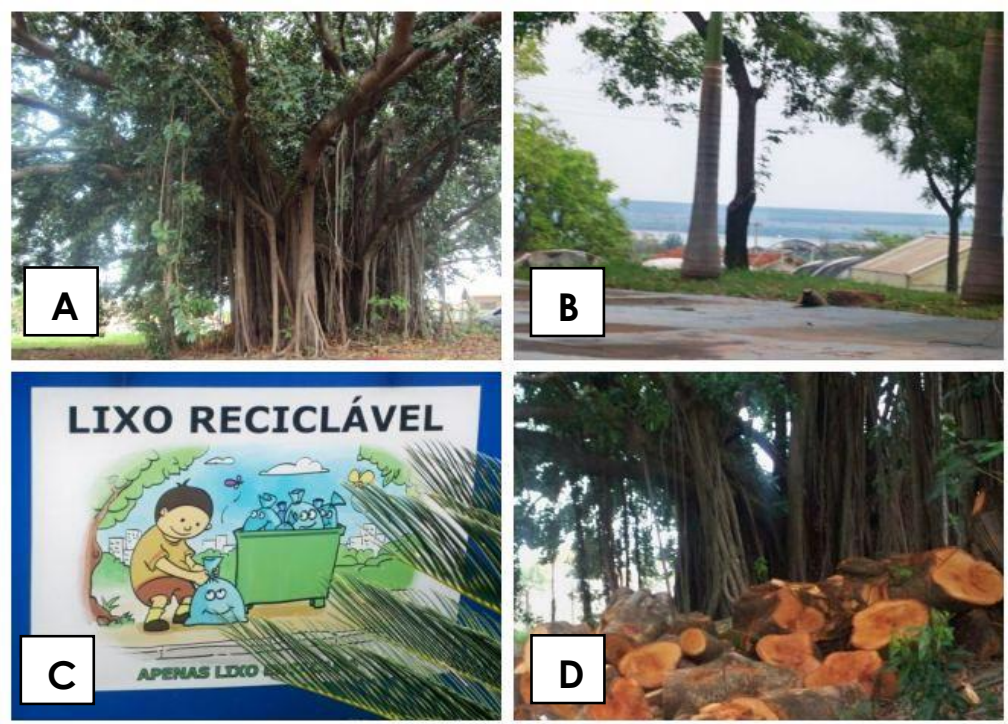

Fonte: Próprio autor. 
Pôde-se observar que tanto nas discussões em sala de aula, quanto na atividade em campo, os alunos se mostraram sensibilizados e curiosos frente às fotografias, a partir deste momento, a maioria dos estudantes pôde se sentir integrante do ambiente, e as imagens que os alunos registraram conseguiram despertar um sentimento de compreensão e cuidado, gerando respostas imediatas, no que se refere aos hábitos de cuidar da natureza, animais, preservar o local como um todo, conforme pode-se observar nas falas a seguir:

Grupo 1. "Passamos por lugares lindos, onde deu até para ver o rio de longe, aqui onde tem as maiores árvores é o melhor lugar, achei agradável a paisagem, gostei muito de tirar as fotos. Escolhemos essas porque acho que representa bem nossa cidade, chama a atenção".

Grupo 2. "Já quase não chove, aqui é quente aí tiram as árvores que fazem ficar fresco, não dá, prejudica muita coisa! Escolhemos essa imagem [figura 3D] porque mostra bem isso, foi o que a gente mais percebeu por aqui".

Para Litz (2009), quando imagens são analisadas, há possibilidade de despertar o aluno a utilizar seus conhecimentos sobre o conteúdo estudado, e, assim, torna-se mais fácil de sensibilizar e atrair a atenção do educando.

Quando questionados sobre o que eles mais gostaram na atividade de campo, pode-se verificar nos relatos que ambos os grupos mencionaram respostas bem diversificadas: desde os "animais encontrados", "análise da paisagem", "poder observar a natureza e tirar fotos a vontade", até respostas relacionadas a aspectos emocionais como: "tranquilidade", "diversão", "aula diferente e prazerosa".

Pode-se verificar que a atividade de campo como recurso didático proporcionou diversos elementos favorecedores ao desenvolvimento do conhecimento geográfico e científico do aluno, contribuindo assim, para ampliar o conhecimento e o interesse do aluno por esta prática, além de trazer para a atividade aspectos emocionais. 


\section{ANÁLISE DAS INTERPRETAÇÕES DOS ESTUDANTES A PARTIR DO GRUPO FOCAL}

Ao todo, foram realizados dois Grupos Focais. É importante indicar que toda a atividade foi conduzida pelos investigadores, os quais foram denominados de moderadores durante a análise das falas. O Grupo Focal teve duração de cerca de 25 a 30 minutos de discussão, sendo filmado e, posteriormente, as falas foram transcritas.

Apesar das dificuldades em conduzir o grupo, devido à timidez dos participantes em relação ao equipamento de gravação, os alunos demonstraram conhecimento adquirido sobre os conceitos abordados durante os encontros e se empenharam em responder as questões que serviram para conduzir a discussão do grupo.

\section{Grupo Focal 1}

Foi possível observar que as questões que nortearam o primeiro Grupo Focal geraram debates que instigaram os alunos de forma positiva, apesar do receio diante dos equipamentos de filmagens e dos moderadores. Tal situação explica o fato dos alunos terem demonstrado um pouco de insegurança durante as primeiras falas, o que abriu espaço para uma discussão sobre qual seria a melhor forma de explicar/definir o que estava sendo questionado.

Durante as discussões foi possível observar que os alunos utilizaram, primeiramente, a ideia de uma "grande área com água", onde as águas subterrâneas dariam origem à bacia hidrográfica de forma sequencial como fica demonstrado nos exemplos transcritos abaixo.

A1. "É uma área grande, com grande quantidade de água"

A2. "É uma bacia de água, tipo uma rede que abastece a cidade"

A3. "Acho que é uma água subterrânea, onde tem muita água, como disseram, aí vários rios dependem desse lugar, ligam um no outro"

A4. "São os rios, um conjunto de rios. Acho que é isso!"

Quando questionados sobre o rio que abastece a região, principais impactos e atividades predominantes, os alunos procuraram investir, no que se refere ao seu discurso, em diferentes passagens explicativas que foram 
abordadas nos encontros anteriores, com intuito de justificar as afirmações mencionadas, como por exemplo, o momento em que citaram o encontro em que foi realizada a confecção das maquetes representando a Bacia Hidrográfica São José dos Dourados. As falas a seguir demonstram tal ponto de vista:

A1. "Pastagens, plantações, a gente fez isso na maquete".

A2. "Verdade! Sei que o nome da nossa bacia é a São José dos Dourados, a gente fez ela mesmo na maquete, onde tem agricultura, essas coisas que ele falou".

A3. "Por isso que o rio é importante, para o abastecimento, essas coisas, a gente mora aqui e depende disso, mesmo não consumindo essa água para beber, dependemos dela".

A4. "Ele também é importante para as indústrias que tem por aqui perto, pra gente, como todo mundo disse".

A5. "Ah, quando a gente montou a maquete também tinha a parte das matas. Nós só colocamos mais os problemas de assoreamento, erosão, essas coisas que podem acontecer se tiver ocupação irregular".

Ao analisar o discurso dos alunos, foi possível constatar principalmente a presença de maior compreensão ao relacionar todos os elementos que podem ser estudadas dentro da temática, foram capazes de identificar os principais impactos encontrados, e as consequências destes, sendo que as ideias sobre conscientização ambiental também foram notórias em vários relatos. Entretanto, tais pensamentos foram utilizados pelos participantes com frequência durante a discussão do grupo, fato que acabou tornando algumas questões repetitivas.

No momento final da discussão, notou-se o importante papel das interações entre os participantes, o que proporcionou informações mais ricas do que as obtidas pelo somatório de respostas individuais originadas da questão anterior.

De acordo com Veiga e Gondim (2001), este tipo de abordagem permite estimular o pensamento científico por parte do aluno, trazendo à tona suas representações, sentimentos e hipóteses sobre o assunto proposto 
pelo moderador do grupo. Caterall; Maclaran e Soares (1997) afirmaram que essa interação em grupo pode permitir o acesso a detalhes de experiências esquecidas pelos participantes ampliando as respostas, além de diminuir a timidez dos participantes, estimulando-os assim, a demonstrar suas opiniões de forma mais intensa. De forma geral, o objetivo maior desta técnica é justamente o de identificar percepções, sentimentos, atitudes e ideias sobre um determinado assunto, o que foi possível de perceber no primeiro Grupo Focal.

\section{Grupo Focal 2}

Durante as discussões do segundo Grupo Focal, evitou-se ao máximo interferir nas respostas, mesmo quando solicitado pelo aluno. Foram comuns respostas finalizadas com perguntas, como "não é isso?" ou "está certo o que eu falei?". Nestes casos, apenas foi informado que não poderia interferir nas respostas e que todas as respostas certas ou erradas, contribuíram como resultados para a pesquisa.

Notou-se que no decorrer da atividade, foram se descontraindo e se envolvendo com o tema, dando opiniões e escutando os demais. Durante as falas foi possível notar a necessidade de menor intervenção dos moderadores, além da maior participação daqueles alunos que nos encontros anteriores não estavam habituados a participar, devido às dificuldades em expressar o que pensavam. Acredita-se que pelo fato de os alunos estarem mais familiarizados com esta técnica, ficaram mais à vontade na exposição de suas ideias durante o último encontro. As opiniões dos alunos acerca das relações entre ecossistemas e bacias hidrográficas foram variadas, como pode ser observado nos relatos a seguir:

A1. "Ecossistemas a gente viu que era toda aquela relação dinâmica entre os seres vivos, o mesmo ocorre nas bacias hidrográficas, não é isso?".

A2. "É, para manter o equilíbrio depende de vários fatores".

A3. "[...] bacias também tem a parte de urbanização e a relação com a natureza, assim como nos ecossistemas, está certo o que eu falei?". 
A4. "As bacias hidrográficas têm rios que abastecem esses lugares, que formam os ecossistemas, onde têm os animais, as pessoas que dependem dessa água. Essa é a relação entre eles eu acho!".

Diante disso, os moderadores relacionaram as respostas dos alunos com questões sobre a função dos animais na manutenção do equilíbrio, a importância das matas ciliares e sua relação com o aspecto da integridade dos rios, a fim de contextualizar a discussão.

A1 "Ah, é a relação entre eles, né? Que deve estar em harmonia para manter o equilíbrio, assim como a nossa, pra manter a bacia hidrográfica livre de riscos".

A2 "É importante porque ela acompanha toda margem do rio..."

A3 "Ela protege, fica em volta, ajuda a evitar o deslizamento".

A4 "Não adianta ter equilíbrio só entre os animais, se a gente não colabora, não tem equilíbrio em nada!".

Os alunos demonstraram maior sensibilidade em visualizar os problemas ambientais. Mencionaram que os impactos negativos sobre 0 ambiente, principalmente os causados pelas ações antrópicas, são reconhecidos como um dos maiores riscos ao ambiente.

A metodologia utilizada permitiu ir além destas primeiras impressões. Segundo Soares (1997), ao utilizar o Grupo Focal, é possível acessar às percepções e às atitudes de pequenos grupos frente a um assunto. Desta forma, foi possível constatar uma pluralidade de falas que de alguma forma enriqueceram as discussões propostas.

Os alunos comentaram sobre a importância da Educação Ambiental para conservação e prevenção dos riscos citados por eles. Quando questionados a respeito da relevância do estudo de bacias hidrográficas e Unidades de Gerenciamento de Recursos Hídricos (UGRHI), apesar das divergências ao explicarem os conceitos, demonstraram segurança em suas falas. De forma sucinta, um aluno comentou que essas Unidades "encarregam-se de pessoas que formam essas unidades e cuidam da distribuição de água em cada região, e garantem a preservação". Outros citaram programas de conscientização para diminuir os impactos negativos, 
como uma das tarefas das Unidades de Gerenciamento. Mencionaram algumas medidas necessárias, como por exemplo: "conscientização não só das pessoas, mas também do governo responsável por tratar o esgoto corretamente e não jogar lixo em locais inapropriados".

Cabe referenciar que a técnica do Grupo Focal nesta pesquisa funcionou como uma lente de zoom sobre os sujeitos, permitindo, como afirma Gatti:

[...] entender melhor as proximidades existentes entre o que as pessoas dizem e o que elas fazem de fato[...]" São essas peculiaridades que ajudam o pesquisador a compreender e teorizar sobre o objeto investigado. Em síntese, o Grupo Focal potencializou o desenvolvimento dessa pesquisa, agraciando-a com um volume qualitativo de dados $e$, dificilmente, outro instrumento de coleta alcançaria tal êxito (GATTI, 2005, p.68).

Considera-se que a aplicação da técnica grupo focal foi bem sucedida, pois foi possível gerar bons momentos de reflexão, tanto aos alunos presentes quanto aos membros do projeto.

A análise das discussões nesses grupos mostrou que a metodologia realmente fornecia subsídios para uma discussão mais ampla, além de possibilitar boas experiências entre os membros do grupo. Assim como assinalaram Morgan e Spanish (1985):

As sessões dos grupos começam com relativa incerteza dos participantes sobre o quanto os pares presentes compartilham de um conjunto de perspectivas sobre o tema a ser discutido. Mas, à medida que os membros do grupo apresentam suas experiências e perspectivas sobre o tema, eles próprios acabam encontrando meios de expressar sua concordância ou discordância com o que está sendo abordado (MORGAN; SPANISH, 1985, p.191).

O roteiro contribuiu de forma eficiente para orientar o levantamento de dados permitindo que as discussões ocorressem de forma homogênea e enriquecedora para a pesquisa, e o mais importante, contando com a participação da maioria dos alunos. Não houve nenhuma recusa em responder às perguntas, porém, no início os alunos demonstraram muita timidez, o que pode ter atrapalhado no desempenho dos mesmos. 
Foi possível observar que as atividades realizadas no projeto, proporcionaram aos alunos a obtenção do conhecimento de forma lúdica e prazerosa além de desenvolver habilidades científicas como a observação, descoberta, comparação, análise e síntese, levando os alunos a despertar a sua curiosidade e o interesse pelas ciências.

Quando questionados sobre o que mais gostaram no projeto, a maioria afirmou que gostou das atividades que foram sendo realizadas ao longo dos encontros, alguns gostaram mais das atividades de campo, enquanto outros mencionaram as aulas em que puderam organizar seus trabalhos com os itens disponíveis no laboratório, como pode ser visto nos depoimentos abaixo:

A1. "As aulas foram bem legais, gostei de tudo".

A2. "Adorei, estudei coisas que não conhecia, visitar os lugares foi a parte mais legal".

A4 "Quando a gente trabalha em grupo parece que aprende mais, porque com os amigos conversando aprendemos muitas coisas".

Outro fator que mostrou o interesse dos alunos foi o fato das atividades terem sido realizadas fora do horário de aula e não contava com a obrigatoriedade de participação, pois, foi oferecido como atividades extracurriculares e todos os alunos da classe participaram ativamente.

\section{CONSIDERAÇÕES FINAIS}

A proposta de trabalhar a Educação Ambiental de maneira interdisciplinar, articulada ao contexto das bacias hidrográficas, proporcionou reflexões que apontam que os objetivos foram alcançados. $O$ trabalho apresenta contribuições significativas para a compreensão das questões ambientais, despertando nos alunos a importância da atuação emancipatória diante das problemáticas socioambientais existentes.

Considera-se que foi alcançado o propósito de levá-los à reflexão crítica sobre as questões ambientais locais e regionais, entretanto, verificouse que os estudantes apresentaram maior facilidade em discutir os problemas ambientais das bacias hidrográficas sob uma perspectiva 
ecológica, abordando-os, muitas vezes, independentes das práticas sociais e econômicas.

Além disso, foi notória a contribuição positiva das atividades práticas propostas, uma vez que o trabalho em campo possibilitou ao aluno entrar em contato direto com a natureza, passar a enxergar e ter a oportunidade de construir seu próprio senso crítico, desprendendo-se, assim, dos livros didáticos inseridos todos os dias em uma sala de aula. O trabalho também possibilitou observar que as práticas pedagógicas e os recursos metodológicos utilizados, atribuíram dinamicidade às atividades junto aos estudantes, constituíram um grande facilitador para 0 processo de aprendizagem e participação dos alunos.

Em relação à metodologia de análise utilizada, corroboramos com Gui (2003) que afirma que a experiência do Grupo Focal é efetiva enquanto instrumento de captação de informações, além das contribuições positivas para a conscientização do potencial das habilidades de trabalho em grupo. Constatou-se que além de favorecer a coleta de dados, esta técnica caracterizou-se como um excelente espaço de reflexão. Os sujeitos da pesquisa consideraram que as interações foram importantes momentos de troca de experiências e reflexão da própria prática como aprendizagem para o grupo.

Entretanto, devido algumas dificuldades já mencionadas, é necessário se atentar aos cuidados que precisam ser adotados, quanto ao tamanho dos grupos, à quantidade de questões discutidas, à profundidade desejada para a discussão e, principalmente, aos riscos de dispersão da conversa e, consequentemente, distanciamento em relação aos propósitos da pesquisa.

Encontramos indícios de que há necessidade de maiores subsídios teóricos e metodológicos para os professores, especialmente de Ciências e Geografia, desenvolverem abordagens educativas dialógicas que sejam capazes de abranger a essência da Educação Ambiental para além da aprendizagem comportamental, que sejam voltadas para a compreensão das questões ambientais, na perspectiva da totalidade do ambiente, desafiando os estudantes para uma permanente análise crítica e 
sensibilização não só de suas próprias ações. Reforçamos assim, a necessidade da abordagem interdisciplinar do tema Bacias Hidrográficas por ter sido possível perceber a abrangência de assuntos que podem surgir a partir do entendimento de sua complexidade.

Diante dessas reflexões, sugerimos a importância de retornar a atenção para a efetivação de políticas públicas voltadas para a formação dos professores e para a reformulação dos currículos escolares, para que ambos possam integrar a Educação Ambiental de forma articulada e proporcionar uma formação ambiental que seja capaz de superar essa fragilidade.

\section{REFERÊNCIAS}

BARDIN, L. Análise de Conteúdo. Lisboa, Portugal; Edições 70, LDA, 2010.

BRASIL. Secretaria de Educação Fundamental. Parâmetros curriculares nacionais: terceiro e quarto ciclos: apresentação dos temas transversais/ Secretaria de Educação Fundamental. Brasília: MEC/SEF, 436 p, 1998.

BEZERRA, T. M. O.; GONÇALVES, A. A. C. Concepções de meio ambiente e educação ambiental por professores da Escola Agrotécnica Federal de Vitória de Santo Antão-PE. Biotemas. 2007, v. 20, n. 3, p. 115-125.

CARVALHO, I. C. M. Em direção ao mundo da vida: interdisciplinaridade e educação ambiental. Brasília: IPÊ - Instituto de Pesquisas Ecológicas, 1998. (Cadernos de Educação Ambiental).

CARVALHO, I. C. M. Educação ambiental: a formação do sujeito ecológico. São Paulo: Cortez, 2008.

CATERALL, M., MACLARAN, P. Focus group data and qualitative analysis programs: coding the moving picture as well as the snapshots. Sociological Research, 1997, v. 2, n. 1. Disponível em: http://www.socresonline.org.uk/2/1/6.html. Acesso em: 17 dez. 2015.

DIAS, G. Educação Ambiental, Princípios e Práticas. São Paulo: Editora Gaia, 1992.

FARINA, B. C., GUADAGNIN, F. Atividades práticas como elemento de motivação para a aprendizagem em geografia ou aprendendo na prática. In: REGO, N., CASTROGIOVANNI, A. C., KAERCHER, N. A. (Org.). Geografia: práticas pedagógicas para o ensino médio. Porto Alegre: Artmed, 2007. 
GATTI, B. A. Grupo focal na pesquisa em ciências sociais e humanas. Brasília, DF: Líber Livro, 2005. 77p.

GUI, R. T. Grupo focal em pesquisa qualitativa aplicada: intersubjetividade e construção de sentido. Rev. Psicol. Organ. Trab. 2003, v.3, n.1, p. 135-159.

LIMA, W. Aprendizagem e classificação social: um desafio aos conceitos.

Revista do ISEP/Programa de Mestrado em Ciências Pedagógicas, 2004, v. 3 , n.1, p. 29-56. Disponível em: http://www.isep.com.br/FORUM5.pdf. Acesso: em 29 abr.2015.

LITZ, V. G. O uso da imagem no Ensino de história. Universidade Federal do Paraná, Caderno Temático do Programa de Desenvolvimento Educacional do Estado do Paraná - PDE. Curitiba, PR. 2009.

MORAES, S. R. et al. O Processo de Diluição de uma Solução como Metodologia Didática. Tchê Química, 2012, v. 9, n. 18, p. 57-64.

MOREIRA, H. E CALEFFE GONZAGA, L. Metodologia da pesquisa para o professor pesquisador. 2 ed. Rio de Janeiro: Lamparina, 2008.

MORGAN, D. L., SPANISH, M. T. Social interaction and the cognitive organisation of health-relevant behaviour. Sociology of Health and IIIness, 1985, n. 7, p. 401-422.

OLIVEIRA, C. D. M.; ASSIS, R. J. S. Travessias da aula em campo na geografia escolar: a necessidade convertida para além da fábula. Educação e Pesquisa, São Paulo, 2009, v. 35, n. 1, p 195-209. Disponível em: http://www.scielo.br> Acesso: em 29 abr.2015.

OLIVEIRA, E. M. Educação Ambiental uma possível abordagem. 2. Ed. Brasília: IBAMA, 2000.

PENTEADO, H.D. Meio ambiente e formação de professores. 4. ed. São Paulo: Cortez, 2001.68p.

REIGOTA, M. Meio ambiente e representação social. $4^{a}$ ed. São Paulo, Cortez, 2001. 87p. (Série Questões da Nossa Época).

REIGOTA, M. Desafios à educação ambiental escolar. In: CASCINO, F.; JACOBI, P.; OLIVEIRA, J.F. Educação, meio ambiente e cidadania. Reflexões e experiências. São Paulo: SMA/CEAM, 1998. p.43-50.

RUFFINO, P. H. P.; SANTOS, S. A. Utilização do conceito de bacia hidrográfica para capacitação de educadores. In: SCHIAVETTI, A.; CAMARGO, A. F. M. (Orgs.). Conceitos de bacias hidrográficas: teorias e aplicações. Ilhéus: Editus, 2002. p. 111-23. 
SOARES, C. B. Adolescentes, drogas e AIDS: avaliando a prevenção e levantando necessidades. 1997. 230p. Tese (Doutorado em administração escolar) - Faculdade de educação, Universidade de São Paulo, São Paulo, 1997.

THIESEN, J. da S. A interdisciplinaridade como um movimento articulador no processo ensino-aprendizagem. Revista Brasileira de Educação. v. 13. n. 39, p.545-598, 2008. Disponível em:

<http://www.scielo.br/pdf/rbedu/v13n39/10.pdf>. Acesso em: 19 dez. 2015.

TOZONI-REIS MFC. Fundamentos teóricos para uma pedagogia crítica da educação ambiental: algumas contribuições. In: $30^{a}$ Reunião anual da Associação Nacional de Pós-Graduação e Pesquisa em Educação; 7-10 out. 2007, Caxambu, MG. Disponível em:

http://www.anped.org.br/reunioes/30ra/trabalhos/GT22-3311-Int.pdf. Acesso em: 19 dez. 2015.

VEIGA, L.; GONDIM, S. M. G. A utilização de métodos qualitativos na ciência política e no marketing político. Opinião Pública. Campinas, v.2, n.1, p.1-15, 2001.

Recebido em: 29 de outubro de 2018 